\title{
EFFECTS OF SEQUENCE PREPARATION OF TITANIUM DIOXIDE-WATER NANOFLUID USING CETYLTRIMETHYLAMMONIUM BROMIDE SURFACTANT AND TiO 2 NANOPARTICLES FOR ENHANCEMENT OF THERMAL CONDUCTIVITY
}

\author{
Eny Kusrini ${ }^{1 *}$, Nandy Putra ${ }^{2}$, Agung Siswahyu ${ }^{1}$, Dewi Tristatini ${ }^{1}$, Wuwuh Wijang Prihandini ${ }^{1}$, \\ Muhammad Idrus Alhamid ${ }^{3}$, Yoki Yulizar ${ }^{4}$, Anwar Usman ${ }^{5}$ \\ ${ }^{1}$ Department of Chemical Engineering, Faculty of Engineering, Universitas Indonesia, Kampus Baru \\ UI, Depok 16424, Indonesia \\ ${ }^{2}$ Applied Heat Transfer Research Group, Department of Mechanical Engineering, Faculty of \\ Engineering, Universitas Indonesia, Kampus Baru UI, Depok 16424, Indonesia \\ ${ }^{3}$ Department of Mechanical Engineering, Faculty of Engineering, Universitas Indonesia, Kampus Baru \\ UI, Depok 16424, Indonesia \\ ${ }^{4}$ Department of Chemistry, Faculty of Mathematics and Natural Sciences, Universitas Indonesia, \\ Kampus Baru UI, Depok 16424, Indonesia \\ ${ }^{5}$ Department of Chemistry, Faculty of Science, Universiti Brunei Darussalam, Jalan Tungku Link, \\ Gadong BE1410, Brunei Darussalam
}

(Received: August 2019 / Revised: October 2019 / Accepted: November 2019)

\begin{abstract}
To maintain the stability of nanofluid from precipitation and agglomeration, some methods such as ultrasonic vibration, adding surfactant, and controlling the $\mathrm{pH}$ value of the system have been studied. Herein, the preparation of titanium dioxide $\left(\mathrm{TiO}_{2}\right)$-water nanofluid, by using $\mathrm{TiO}_{2}$ nanoparticles $\left(\mathrm{TiO}_{2} \mathrm{NPs}\right)$ and the cationic surfactant cetyltrimethylammonium bromide (CTAB), was investigated to determine the effects of the sequence method on the preparation of $\mathrm{TiO}_{2}-$ water nanofluid, its thermal conductivity, its stability, and its temperature distribution. NPs can improve the efficiency of heat transfer fluids and improving the stability of colloidal systems. Some parameters were varied, including sonication times of 5, 10, and 30 minutes, variations of $\mathrm{TiO}_{2}$ loading in $1-8 \%$ volumetric loading, concentrations of CTAB $(0.005-0.035 \mathrm{wt} \%)$, and $\mathrm{pH}$ at 8-12. The procedure sequences of 2 and 5 showed the distribution particle size of $\mathrm{TiO}_{2}$ nanoparticles in nanofluid had a narrow range $(190.3-208.7 \mathrm{~nm})$ compared to other sequence methods $(611 \mathrm{~nm}-5.35 \mu \mathrm{m})$. The procedure sequence of 2 is following demineralized water $(100$ $\mathrm{mL}$ ), $8 \%$ volumetric loading of $\mathrm{TiO}_{2} \mathrm{NPs}$, ultrasonication time of $10 \mathrm{~min}$ and CTAB of $3.2 \times 10^{-3}$ $\mathrm{M}$, while the procedure sequence of 5 is in the respective order of demineralized water $(100 \mathrm{~mL})$, $8 \%$ volumetric loading of $\mathrm{TiO}_{2} \mathrm{NPs}$, ultrasonication time of $10 \mathrm{~min}$ and $\mathrm{pH}$ at 8 . The CTAB surfactant $(0.029 \mathrm{wt} \%)$ had a greater influence on particle distribution in the nanofluid than the $\mathrm{pH}$. The thermal conductivities of the nanofluid were characterized with $\mathrm{TiO}_{2}$ nanofluid as the working fluid. The experimental results showed a maximum of $21 \%$ thermal conductivity enhancement for $8 \%$ volumetric loading of $\mathrm{TiO}_{2} \mathrm{NPs}$ at $\mathrm{pH} 8$ and fourfold increase in critical micelle concentration $(0.029 \mathrm{wt} \%)$ from $\mathrm{CTAB}$. These findings offer the potential for preparing a stable $\mathrm{TiO}_{2}$-water nanofluid with a short ultrasonic time of 10 minutes. This process is a desirable and very useful to obtain a stable $\mathrm{TiO}_{2}$-water nanofluid with a short ultrasonic time for efficient process and low-cost nanofluid with high
\end{abstract}

\footnotetext{
${ }^{*}$ Corresponding author's email: ekusrini@che.ui.ac.id, Tel. +62-21-7863516 ext. 204, Fax: +62-21-7863515 Permalink/DOI: https://dx.doi.org/10.14716/ijtech.v10i7.3758
} 
thermal conductivity and stability.

Keywords: Cationic surfactant; Concentration of CTAB; Thermal conductivity; $\mathrm{TiO}_{2}$-water nanofluid; Ultrasonic time

\section{INTRODUCTION}

The development of high-performance heat transfer fluids using nanoparticles (NPs) has been interesting to investigate in detail (Ahlatli et al., 2016). It is well known that nanofluid, a colloidal mixture produced from a base fluid and a nanoparticle, has valuable heat transfer applications and is among a new generation of heat transfer fluids that enhance thermal conductivity. Studies of various parameters (such as particle size, concentration, temperature, material type and base fluid type) to enhance heat transference have been performed (Putra et al., 2012; Yiamsawasd et al., 2012; Saleh et al., 2013; Ismay et al., 2013). NPs can improve the efficiency of heat transfer fluids (Zhou et al., 2012; Saleh et al., 2013), as their high surface energy makes them easy to coagulate and difficult to disperse in base fluids, improving the stability of colloidal systems (Zhou et al., 2012). The stability of colloidal suspensions of micro and nanosized particles is dependent on the surface force between particles (namely, the zeta potential) that is influenced by $\mathrm{pH}$ value (Ismay et al., 2013). Das et al. (2018) experimentally investigated the stability measurement of anatase- sodium dodecyl sulfate (SDS) and anatase-cetyltrimethylammonium bromide (CTAB) nanofluids, which had observable zeta potentials of $-17.8 \mathrm{mV}$ and $-21.1 \mathrm{mV}$, respectively. Therefore, anatase-CTAB nanofluid was found to have marginally better stability than the anatase-SDS nanofluid.

The agglomeration of $\mathrm{TiO}_{2}$ NPs settles and clogs microchannels as well as decreasing the thermal conductivity of nanofluid (Yu \& Xie, 2012; Ismay et al., 2013). Many investigations have been conducted to produce a more stable colloidal and suspension of nanofluid. To maintain the stability of nanofluid from precipitation and agglomeration, some methods (such as ultrasonic vibration, adding surfactant, and controlling the $\mathrm{pH}$ value of the system) have been reported (Duangthongsuk \& Wongwises, 2009). A well-known and effective method to homogenize dispersed NPs in base fluids is adding surfactant (Jiang et al., 2003; Xie et al., 2003; Murshed et al. 2005; Zhou et al., 2012).

The effects of surfactants (such as CTAB, acetic acid (AA), oleic acid (OA), and SDS) on $\mathrm{TiO}_{2}-$ water nanofluid have been studied and findings have shown that CTAB and AA provided stable suspensions (Das et al., 2016; Adiwibowo et al., 2018). The $\mathrm{TiO}_{2}$ solid fraction has been varied between $0.1-2.0 \%$ while temperatures have ranged from 20 to $60^{\circ} \mathrm{C}$ (Das et al., 2016). Murshed et al. (2005) reported enhanced thermal conductivity (up to 33\%) for deionized water by adding $\mathrm{TiO}_{2} \mathrm{NPs}$ (5\% volume fraction). That being said, $\mathrm{TiO}_{2} \mathrm{NPs}$ have also been reported as causing dye degradation (Rahman et al., 2018; Zulmajdi et al., 2019).

In a previous study, the cationic surfactant CTAB was investigated for its ability to break down particle agglomeration in a suspension and was found more effective than oleic acid (Murshed et al., 2005). However, the $\mathrm{TiO}_{2}$ nanofluid by ultrasonic process for 8 to 10 hours (Murshed et al., 2005). On the other hand, Duangthongsuk and Wongwises (2009) investigated the preparation of $\mathrm{TiO}_{2}$ nanofluid by using ultrasonic within 2 hours. As noted here that the time for preparation of $\mathrm{TiO}_{2}$ nanofluid is too long in the range 2 to 10 hours.

Therefore, to reduce the ultrasonic times in preparation of $\mathrm{TiO}_{2}-$ water nanofluid during the ultrasound process, the proper mixing, stabilization and also dispersion of $\mathrm{TiO}_{2} \mathrm{NPs}$ in water are very important to investigate for producing the stable of $\mathrm{TiO}_{2}$-water nanofluid. In this study, improving and increasing the thermal conductivity of $\mathrm{TiO}_{2}-$ water nanofluid and the optimum thermal conductivity from $\mathrm{TiO}_{2}$-water nanofluid with short time sonication were studied. The 
effect of $\mathrm{CTAB}$ in $\mathrm{TiO}_{2}$-water nanofluid formulation and the effect of sequence preparation methods in growth of particle size in $\mathrm{TiO}_{2}$-water nanofluid were also studied in detail. The experimental results and theoretical predictions from the Maxwell (1873) and Bhattacharya et al. (2004) models were also compared.

\section{EXPERIMENTAL}

\subsection{Materials}

The $\mathrm{TiO}_{2}$ NPs (Degussa P25) used had a particle size of $21 \mathrm{~nm}$ and a density of $130 \mathrm{~g} / \mathrm{L} . \mathrm{NaOH}$ was purchased from Merck (Germany) and was used for $\mathrm{pH}$ adjustment. CTAB $\left(\mathrm{C}_{19} \mathrm{H}_{42} \mathrm{BrN}\right)$ with a molecular weight of $364.45 \mathrm{~g} / \mathrm{mol}$ and a critical micelles concentration (CMC) of about $8 \times 10^{-4}$ $\mathrm{M}$ was used to stabilize the $\mathrm{TiO}_{2}$ nanofluid.

\subsection{Characterization of Thermal Conductivity of $\mathrm{TiO}_{2}$-water Nanofluid}

The thermal conductivity of $\mathrm{TiO}_{2}$-water nanofluid was measured with a KD2 portable thermal analyzer (hot wire type) with a 2-minute measurement speed, a $60-\mathrm{mm}$ long sensor with a diameter of $1.28 \mathrm{~mm}$, and a $72 \mathrm{~cm}$ length of wire. Characterization and its measurement for thermal conductivity were according to the Saleh et al. (2014). The sensor contained an integrated heating element and thermo-resistor and was linked to a microprocessor to control and conduct measurements. The thermal conductivity sensor had to be dipped into the nanofluid system, which was placed in a thermostatic circulating bath (TCB) to maintain a constant temperature of $25^{\circ} \mathrm{C}$ for all measurements. Threefold measurements were conducted for each nanofluid to ensure the reliability of the thermal conductivity measurements.

\subsection{Preparation of $\mathbf{T i O}_{2}$-water Nanofluid with Various Concentrations}

$\mathrm{TiO}_{2}$-water nanofluids were synthesized with an identical mixing method using starting materials at desired concentration levels prior to being sonicated using ultrasonic instrument. $\mathrm{TiO}_{2} \mathrm{NPs}_{\mathrm{S}}$ concentrations from 1 to $8 \%$ volumetric loading were added to $100 \mathrm{~mL}$ of demineralized water before being mixed using an ultrasonic method for times of 5, 10, and 30 minutes.

The best and optimum ultrasonic time for preparation of $\mathrm{TiO}_{2}$-water nanofluid was 10 minutes. Thus, we used the optimum time for further preparation of $\mathrm{TiO}_{2}$ nanofluid. Thermal conductivity of nanofluid was then measured, followed by our selection of the highest thermal conductivity from the samples for further study. The best concentration of $\mathrm{TiO}_{2} \mathrm{NPs}$ with the highest thermal conductivity was obtained at an $8 \%$ volume fraction.

\subsection{Preparation of $\mathrm{TiO}_{2}$-water Nanofluid with Various pH}

The best $\mathrm{TiO}_{2} \mathrm{NPs}$ concentration of $8 \%$ volume fraction was selected for further study at various $\mathrm{pH}$ from $8-12$. The $\mathrm{pH}$ was adjusted using a $\mathrm{NaOH}$ solution and measured using a $\mathrm{pH}$ meter. All thermal conductivities of $\mathrm{TiO}_{2}$-water nanofluid were recorded using a TCB. The best $\mathrm{pH}$ value of nanofluid with the highest thermal conductivity was 8 .

\subsection{Preparation of $\mathrm{TiO}_{2}$-water Nanofluid with Addition of Cationic Surfactants}

Nanofluids at various CMCs (1-6) were synthesized by adding CTAB. The CMC of CTAB was $8 \times 10^{-4} \mathrm{M}$. Thermal conductivities of nanofluid prepared were measured using the TCB. The highest thermal conductivity of nanofluid with a CMC of CTAB was fourfold. Considering the results, a fourfold $\mathrm{CMC}$, a $\mathrm{TiO}_{2} \mathrm{NPs}$ concentration of $8 \%$ volumetric loading, and a $\mathrm{pH}$ value of 8 were chosen for nanofluid preparation analysis under a combination of sequence methods. The CMC of CTAB was calculated as follows:

$$
\mathrm{CMC}=(\text { amount of surfactant/molecular weight }) \times(1000 / \text { volume of solvent })
$$




\subsection{Characterizations}

Enhancement of Thermal Conductivity

Particle size distributions of samples were measured by using the Particle Size Analyzer (PSA), Zetasizer Nano series (Malvern ZEN 1600). The ultrasound process was conducted with a Sonicator Ultrasonic Processor (Brand Chrome Tech, type UP-800, size Tip $13 \mathrm{~mm}, 800$ watt). The thermal conductivity of $\mathrm{TiO}_{2}-$ water nanofluid was measured with a KD2 portable thermal analyzer (hot wire type).

\section{RESULTS AND DISCUSSION}

\subsection{Thermal Conductivity of the Base Fluids and $\mathrm{TiO}_{2}$-Water Nanofluid with Various Concentrations and Ultrasonic Time}

The thermal conductivity of demineralized water as a base for the nanofluid under the experimental conditions is listed in Table 1 . At $25-40^{\circ} \mathrm{C}$, the thermal conductivity of demineralized water was found in the range of 0.57-0.63. A TCB was used to measure the thermal conductivity during measurement samples while maintaining a temperature of $25^{\circ} \mathrm{C}$. When measuring $\mathrm{pH}$ from 8 to 14 , the thermal conductivity remained constant (0.57). Adding the CTAB surfactant with a CMC from 4 to 10 in base fluids, the thermal conductivity also remained constant. Increasing the CMC of CTAB only decreased the $\mathrm{pH}$, because the concentration of CTAB cationic surfactant caused an increase in positive charge thus the fluid is more acid.

Table 1 Thermal conductivity of demineralized water as base fluid in nanofluids in several experimental conditions

\begin{tabular}{cccccccc}
\hline No & $\mathrm{T}\left({ }^{\circ} \mathrm{C}\right)$ & $\mathrm{K}$ & $\mathrm{pH}$ & $\mathrm{K}$ & $\mathrm{CMC}(\mathrm{x})$ & $\begin{array}{c}\mathrm{pH} \text { water }+ \\
\text { CTAB }\end{array}$ & $\begin{array}{c}\mathrm{K} \text { water }+ \\
\mathrm{CTAB}\end{array}$ \\
\hline 1 & 25 & 0.57 & 8 & 0.57 & 4 & 5.80 & 0.57 \\
2 & 30 & 0.59 & 10 & 0.57 & 6 & 5.68 & 0.57 \\
3 & 35 & 0.61 & 12 & 0.57 & 8 & 5.56 & 0.57 \\
4 & 40 & 0.63 & 14 & 0.57 & 10 & 5.52 & 0.57 \\
\hline
\end{tabular}

where $\mathrm{K}$ : thermal conductivity, CMC: critical micelles concentration

Sonawane et al. (2015) investigated $\mathrm{TiO}_{2}$-water nanofluid with optimum sonication times of 60 minutes with a $6 \%$ volume fraction of $\mathrm{TiO}_{2} \mathrm{NPs}$, confirming a $22 \%$ enhancement in thermal conductivity. In this study, a $\mathrm{pH}$ of 8 , a fourfold $\mathrm{CMC}$, a constant temperature of $25^{\circ} \mathrm{C}$, and sonication for 10 minutes (see Figure 1) were used as control parameter conditions. $\mathrm{TiO}_{2} \mathrm{NPs}$ were used to increase the base thermal conductivity of demineralized water. The best performance of $\mathrm{TiO}_{2}$-water nanofluid was synthesized at an $8 \%$ volume fraction of NPs, a sonication process of 10 minutes, and an addition of CTAB $(0.029 \mathrm{wt} \%)$. Sonication was used to improve the dispersion (Prasher et al., 2006) of $\mathrm{TiO}_{2}$ NPs. The thermal conductivity enhancement was due to the increase in ultrasonic time from 0 minutes to 10 minutes. The Brownian motion of NPs and the intermolecular interaction between particles and fluids in the nanofluids increased after the optimum time increased from 10 to 30 minutes. The clustering of NPs started, which accounted for the decrement in primary NPs for heat transport and thermal conductivity. It is believed that heat transfer is a surface phenomenon and that the surface of NPs is used for thermal energy interaction (Sonawane et al., 2015). When the particles started to agglomerate, the effective surface area to volume ratio decreased, resulting in a reduction of the effective transfer area of particles and causing a decrease in the thermal conductivity of the fluid (Sonawane et al., 2015). 


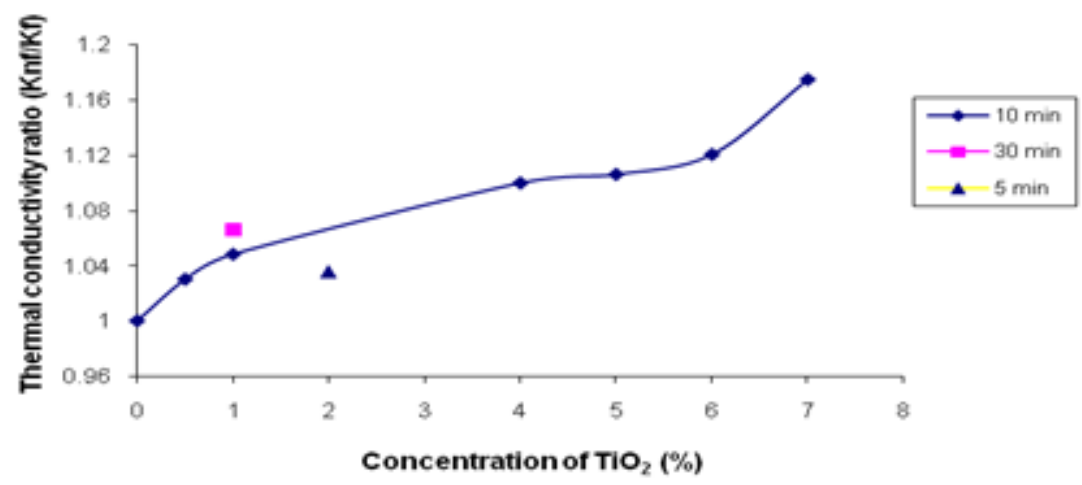

Figure 1 Effect of ultrasonic time on thermal conductivity at room temperature

Figure 2 shows the thermal conductivity ratio of $\mathrm{TiO}_{2}$-water nanofluid as a function of NPs volume concentration. The addition of $\mathrm{TiO}_{2} \mathrm{NPs}$ to the base fluids enhanced their thermal conductivity from 3 to $21 \%$ (Figure 2). The experimental results show a maximum of $21 \%$ thermal conductivity enhancement for an $8 \%$ volume fraction of $\mathrm{TiO}_{2} \mathrm{NPs}_{\text {. }} \mathrm{The}^{\mathrm{TiO}_{2} \mathrm{NPs} \text { was }}$ well dispersed into the base fluids, making the thermal conductivity of the $\mathrm{TiO}_{2} \mathrm{NPs}_{\text {greater }}$ than the base fluids. Thermal conductivity enhancement can be achieved if the Brownian motion present and occurred in the system (Prasher et al., 2006). Brownian motion caused the colloidal particles to be uniformly dispersed in the base fluids and $\mathrm{TiO}_{2} \mathrm{NPs}$ could not be separated from the dispersion when silenced. This observation provides greater value than previous research, confirming that as much as $5.8 \%$ thermal conductivity enhancement is achieved with a $2 \%$ volume fraction of $\mathrm{TiO}_{2}$ NPs at 2 hours of sonication time (Sonawane et al., 2015).

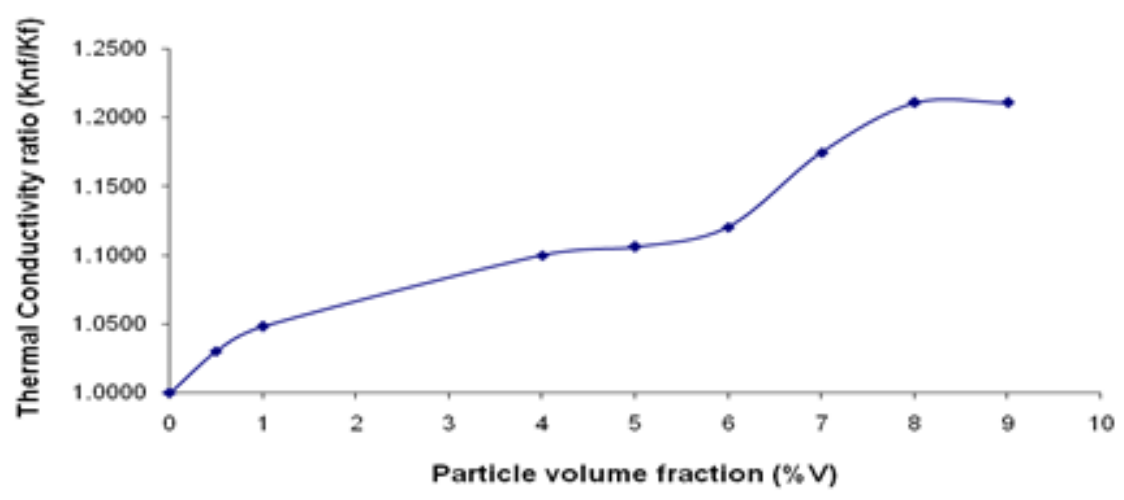

Figure 2 Enhancement of thermal conductivity of $\mathrm{TiO}_{2}-$ water nanofluids with the demineralized water as base fluid

The increased thermal conductivity was influenced by NPs size, shape, and properties as well as the interaction between NPs and the base fluid surface, which caused cluster formation (Xie et al., 2003; Leong et al., 2006). Our study results showed thermal conductivity increasing linearly with increasing amounts of $\mathrm{TiO}_{2} \mathrm{NPs}$, reaching an optimal thermal conductivity ratio at $8 \%$ volume fraction. These results are similar to thermal conductivity increases achieved with $\mathrm{Fe}$ nanofluid using a base of ethylene glycol reported by Hong et al. (2005).

Both the experimental data and the theoretical results from the Maxwell (1873) and Bhattacharya et al. (2004) models showed that the thermal conductivity of $\mathrm{TiO}_{2}-$ water nanofluid increased with the volume fraction of $\mathrm{TiO}_{2} \mathrm{NPs}$. The thermal conductivity predictions for $\mathrm{TiO}_{2}-$ water nanofluid obtained using the Maxwell model were similar to the results from this study. Both differed from predictions proposed under the Bhattacharya model (see Figure 3). 


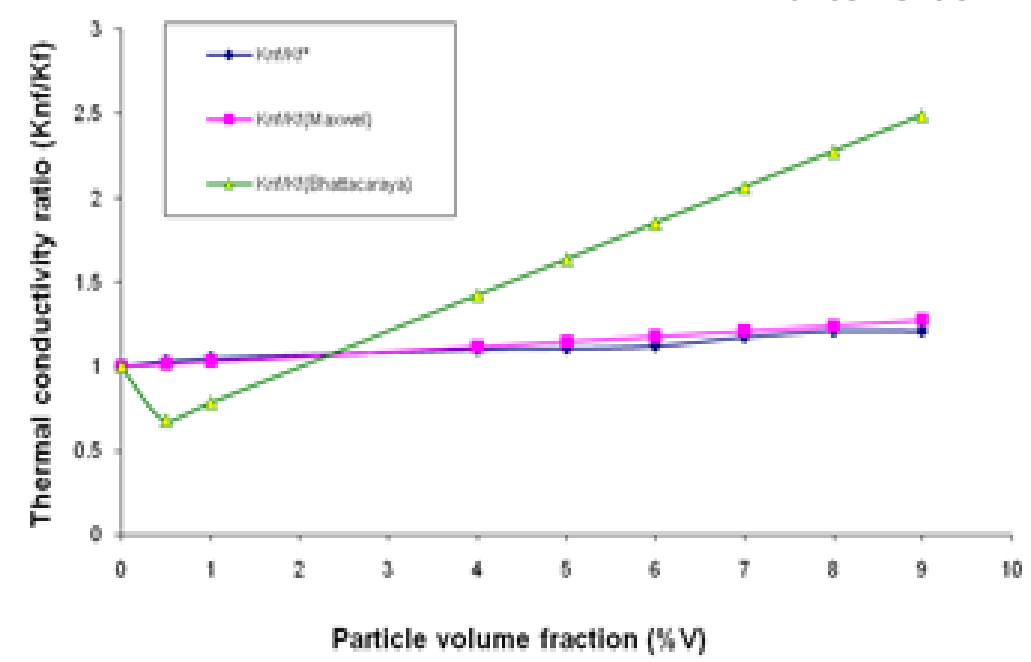

Figure 3 Comparison thermal conductivity between theoretical predictions by the Maxwell and Bhattacharya models as well as resulting experimentation $\left(\mathrm{K}_{\mathrm{NF} / \mathrm{K}_{\text {water }}}{ }^{*}\right)$

\subsection{Thermal Conductivity of $\mathrm{TiO}_{2}$-Water Nanofluid with Various $\mathrm{pH}$}

In this study, $\mathrm{pH}$ value adjustment was used to modify the base fluid and the surface of the $\mathrm{TiO}_{2}$ NPs, providing electrostatic repulsive force to offset the van der Waals forces between particles, so that NP aggregation did not occur (Li et al., 2008). Increasing the $\mathrm{pH}$ value enhanced thermal conductivity due to the increase in electrostatic charge on the particle surface (Li et al., 2008). However, our study showed that increasing $\mathrm{pH}$ values did not influence the thermal conductivity of $\mathrm{TiO}_{2}$-water nanofluid. At the optimal $\mathrm{TiO}_{2} \mathrm{NPs}$ volume fraction of $8 \%$, we evaluated the effects of $\mathrm{pH}$ value on thermal conductivity for the $\mathrm{TiO}_{2}$-water nanofluid. We noted that the changing of $\mathrm{pH}$ values did not influence the thermal conductivity when compared with the base fluid. Changing the $\mathrm{pH}$ value from 8 to 12 actually reduced the thermal conductivity ratio $\left(\mathrm{K}_{\mathrm{nf}} / \mathrm{K}_{\mathrm{f}}\right)$ of the nanofluid from 1.211 to 1.158 . The increased $\mathrm{pH}$ value meant that a higher concentration of $\mathrm{NaOH}$ reduced the electrical double layer, causing decreased electrostatic repulsive force. Consequently, agglomeration would form and reduce thermal conductivity. The effects of $\mathrm{pH}$ value on the thermal conductivity of the $\mathrm{TiO}_{2}$-water nanofluid is presented in Figure 4.

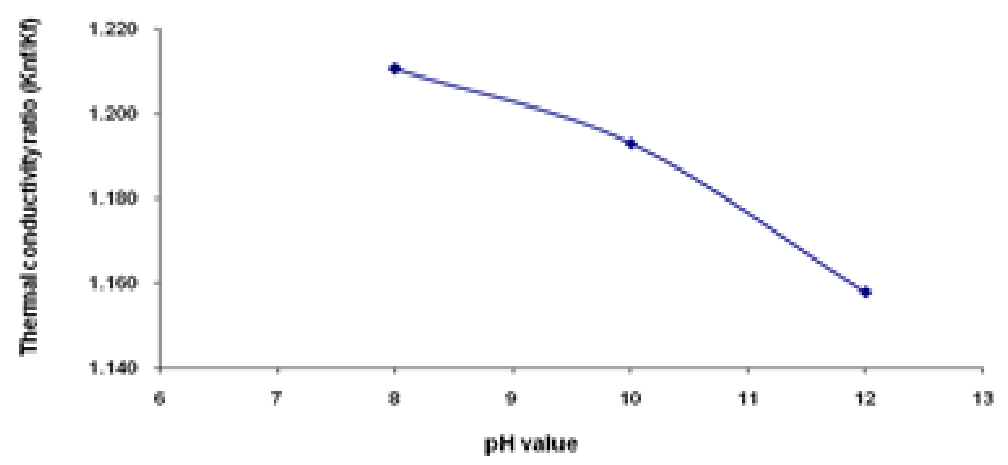

Figure 4 Effects of $\mathrm{pH}$ value on the thermal conductivity of $\mathrm{TiO}_{2}$-water nanofluid

\subsection{Thermal Conductivity of $\mathrm{TiO}_{2}$-Water Nanofluid with the Addition of Cationic Surfactant}

Surfactant was added to the base fluid to reduce particle agglomeration and aggregation (Zhou et al., 2012), as well as clusters, increasing stability and enhancing the dispersion of $\mathrm{TiO}_{2} \mathrm{NPs}$ into the base fluid. The optimum amount of CTAB surfactant added to the base fluid is presented in Figure 5a. It was determined that adding cationic surfactant (CTAB) at rates higher than fourfold 
of the $\mathrm{CMC}$ would reduce the thermal conductivity of $\mathrm{TiO}_{2}$-water nanofluid. We found that the CMC of CTAB surfactant was about $8 \times 10^{-4} \mathrm{M}$, a smaller value than that found in determining CTAB surfactant through the fiber refractive index sensor principle, which was about $9.11 \times 10^{-4}$ M (Zhen-Jian et al., 2010).

At a fourfold CMC, CTAB surfactant formed micellar, which attached to the $\mathrm{TiO}_{2} \mathrm{NPs}$. This layer may have offset the Van der Waals force, which prevented the deposition and maintained the thermal conductivity ( $\mathrm{Yu} \& \mathrm{Xie}, 2012)$. The thermal conductivity decreased when we used CTAB surfactant at a greater than fourfold CMC (0.029 wt \%). This occurred because of the nanofluid containing more cationic nitrogen $\left(\mathrm{N}^{+}\right)$, causing a shift in the $\mathrm{pH}$ value from $\mathrm{TiO}_{2}-$ anatase ( $\mathrm{pH}$ 6.4) toward the point of zero charge (PZC). When the $\mathrm{pH}$ value approached PZC, the particle charge and steric repulsive force would be lost, causing particles to stick together and decreasing thermal conductivity (Zhu et al., 2008). These results are similar to those reported by Wang et al. (2009), who indicated that increased SDBS (sodium dodecylbenzene sulfonate) surfactant into an $\mathrm{Al}_{2} \mathrm{O}_{3}$-deionised water nanosuspension also produced swiftly decreasing thermal conductivity ratios. The SDBS concentrations of 0.1 and $0.07 \%$ were deemed optimal concentrations for $0.1 \% \mathrm{Al}_{2} \mathrm{O}_{3}$ and $0.1 \% \mathrm{Cu}$ nanosuspensions, respectively (Wang et al., 2009).

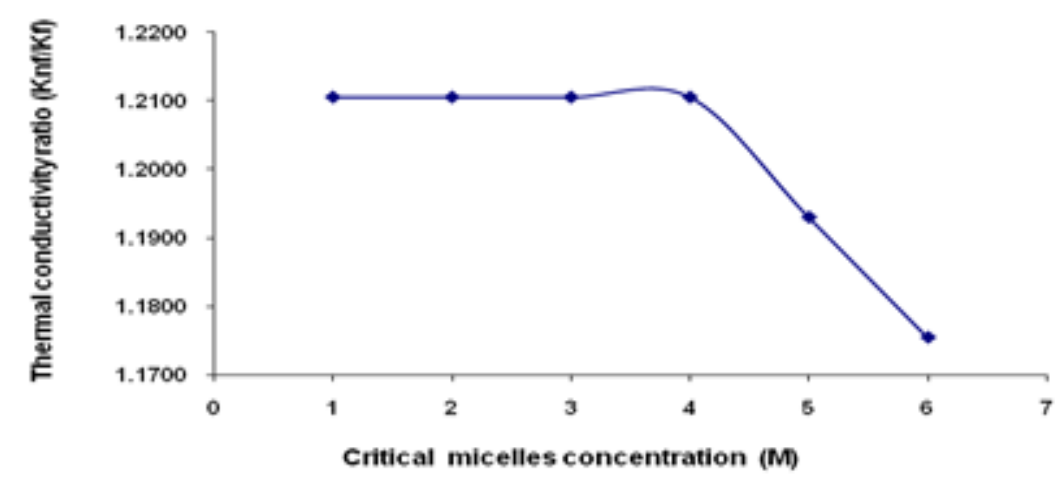

(a)

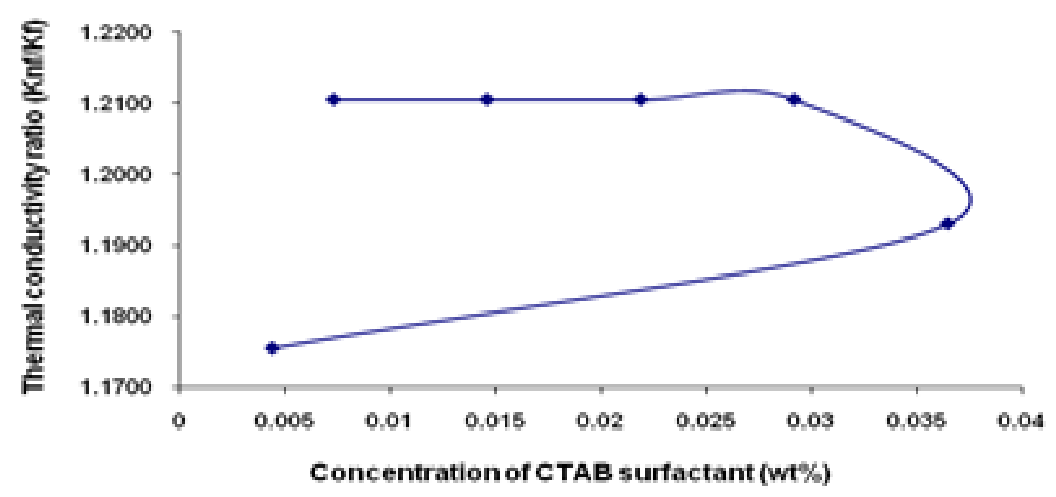

(b)

Figure 5 (a) Effects of CTAB surfactant on the thermal conductivity of $\mathrm{TiO}_{2}$-water nanofluids vs. critical micelles concentration; (b) thermal conductivity ratio vs. CTAB concentrations

Murshed et al. (2005) reported that CTAB surfactant could improve stability and provide good dispersion in fluids without influencing the thermo-physical properties of a nanofluid while also providing heat transfer performance if a very low concentration of CTAB $(0.01-0.02 \mathrm{wt} \%)$ was used. We observed that the effects of surfactant concentration on the thermal conductivity ratio of the surfactant solution at room temperature was similar to concentrations ranging from 0.0073 to $0.029 \mathrm{wt} \%$ and that the ratio started to decrease after CTAB surfactant concentrations reached $0.0365 \mathrm{wt} \%$ (Figure 5b). At low concentrations of CTAB surfactant, the thermal conductivity 
ratio remained stable. The cationic surfactant linked to itself in the base fluids while the water molecules bonded to the CTAB surfactant chain influence, networking the water molecules (Zhou et al., 2012). We noted that thermal conductivity decreased due to the dynamic cross-linking and united adjacent chains (Jayasree et al., 2006).

\subsection{Sequence Method Analysis for Preparing of $\mathrm{TiO}_{2}$-Water Nanofluid}

To obtain the optimum parameters when preparing of $\mathrm{TiO}_{2}$-water nanofluid by varying $\mathrm{pH}$ values and CTAB surfactant, combinations of preparation methods were investigated to determine the effects of nanofluid thermal conductivity and stability. A summary of the experimental sequence methods for preparing $\mathrm{TiO}_{2}-$ water nanofluid with demineralized water as a base fluid and an $8 \%$ volume fraction of $\mathrm{TiO}_{2} \mathrm{NPs}$ is given in Table 2.

To observe the effect of sequences and typical preparation methods in the growth of $\mathrm{TiO}_{2}$-water nanofluid particle size, estimations were made using a PSA after two weeks the $\mathrm{TiO}_{2}$-water nanofluids were prepared. Among the seven of sequence procedures (see Table 2), the procedure sequences numbered 2 and 5 showed particle size distributions for the NPs in the $\mathrm{TiO}_{2}-$ water nanofluid system within a narrow range when compared to the other methods. The procedure sequence of 2 is following demineralized water $(100 \mathrm{~mL}), 8 \%$ volumetric loading of $\mathrm{TiO}_{2} \mathrm{NPs}_{\text {, }}$ ultrasonic time of $10 \mathrm{~min}$ and $\mathrm{CTAB}$ of $3.2 \times 10^{-3} \mathrm{M}$, while the procedure sequence of 5 is in the respective order of demineralized water $(100 \mathrm{~mL}), 8 \%$ volumetric loading of $\mathrm{TiO}_{2} \mathrm{NPs}$, ultrasonic time of $10 \mathrm{~min}$ and $\mathrm{pH}$ at 8 .

Table 2 The procedure sequence to prepare of $\mathrm{TiO}_{2}$-water nanofluids

\begin{tabular}{ccccccc}
\hline & \multicolumn{7}{c}{ Procedure } \\
\cline { 2 - 7 } Sequence & $\begin{array}{c}\text { Demineralized } \\
\text { water }\end{array}$ & $\begin{array}{c}\mathrm{TiO}_{2} \text { NPs } \\
(8 \%)\end{array}$ & $\begin{array}{c}\text { Ultrasonic } \\
\text { time }(10 \text { min) }\end{array}$ & $\begin{array}{c}\mathrm{CTAB}(4 \times \\
\mathrm{CMC})\end{array}$ & $\mathrm{pH} 8$ & $\begin{array}{c}\text { Particle Size } \\
\text { Distribution after } \\
2 \text { weeks (nm) }\end{array}$ \\
\hline 1 & $v$ (i) & $v$ (ii) & $v$ (iii) & - & - & 611.6 \\
$\mathbf{2}$ & $v$ (i) & $v$ (ii) & $v$ (iii) & $v$ (iv) & - & $\mathbf{1 9 0 . 3}$ \\
3 & $v$ (i) & $v$ (ii) & $v$ (iv) & $v$ (iii) & - & 5,346 \\
4 & $v$ (i) & $v$ (ii) & $v$ (iii) & - & $v$ (iv) & $869 ; 188.1$ \\
$\mathbf{5}$ & $v$ (i) & $v$ (ii) & $v$ (iv) & - & $v$ (iii) & $\mathbf{2 0 8 . 7}$ \\
6 & $v$ (i) & $v$ (ii) & $v$ (iii) & $v$ (iv) & $v$ (v) & 1,181 \\
7 & $v$ (i) & $v$ (ii) & $v$ (v) & $v$ (iv) & $v$ (iii) & 2,113 \\
\hline
\end{tabular}

Note: Numbers (i), (ii, iii), (iv), and (v) are to show the sequences of procedure. The bold type indicated the best sequence method in preparing of $\mathrm{TiO}_{2}$-water nanofluid

Sequence procedure 2 exhibited a particle size distribution of $\mathrm{NPs}$ in $\mathrm{TiO}_{2}$-water nanofluid of $190.3 \mathrm{~nm}(94.8 \%$; Figure 6a). Sequence procedure 5 showed a particle size distribution of 208.7 $\mathrm{nm}(96.7 \%$; Figure $6 \mathrm{~b})$. The other methods showed the particle sizes distribution in the range of $611 \mathrm{~nm}$ to $5.35 \mu \mathrm{m}$. We observed that sequence procedure 1 and 4 gave better particle sizes distribution compared to sequence procedures 3 and 7 . In sequence procedure 1 , we prepared the $\mathrm{TiO}_{2}$-water nanofluid without adding $\mathrm{CTAB}$ surfactant and found that the particle sizes distribution of $\mathrm{TiO}_{2} \mathrm{NPs}$ was $611.6 \mathrm{~nm}$. Here, the $\mathrm{pH}$ value was affected more by the particle sizes distribution than the CTAB surfactant. In sequence procedure 4 , the particle size distribution had a large range from 188.1 to $869 \mathrm{~nm}$. In sequence methods 4 and 5, we only observed the effect of ultrasonic time and $\mathrm{pH}$ without adding CTAB surfactant. Had we used CTAB surfactant and $\mathrm{pH}$ value simultaneously, the particle size distribution of $\mathrm{TiO}_{2} \mathrm{NPs}$ would have been higher when compared to the preparation of $\mathrm{TiO}_{2}$-water nanofluid that only had CTAB surfactant added and/or an adjusted $\mathrm{pH}$ value. The deposition and precipitation process was accelerated, causing 
damage to the micelle system due to the heat from the sonication process (Assael et al., 2005, Murshed et al., 2008). The double layer that formed from the steric stability gave greater force than the double layer formed from electrostatic stability when the $\mathrm{pH}$ was adjusted, causing steric stability to form micelles between NPs (Yu \& Xie, 2012).

Due to the PZC (Jin et al., 2009) of $\mathrm{TiO}_{2}$ NPs being an acidic $\mathrm{pH}$ position, if we use an acidic condition, $\mathrm{TiO}_{2} \mathrm{NPs}$ immediately precipitate because the surface of the $\mathrm{TiO}_{2}$ has no charge. Thus, we adjusted the $\mathrm{pH}$ value to a base and the surface of $\mathrm{TiO}_{2} \mathrm{NPs}$ absorbed a number of similar anions. This produced a repulsive force among $\mathrm{TiO}_{2} \mathrm{NPs}$, keeping the $\mathrm{TiO}_{2} \mathrm{NPs}$ away from each other and preventing agglomeration. However, the application of a heat exchange system is not recommended under an acidic $\mathrm{pH}$ condition, which can damage the heat pipe.
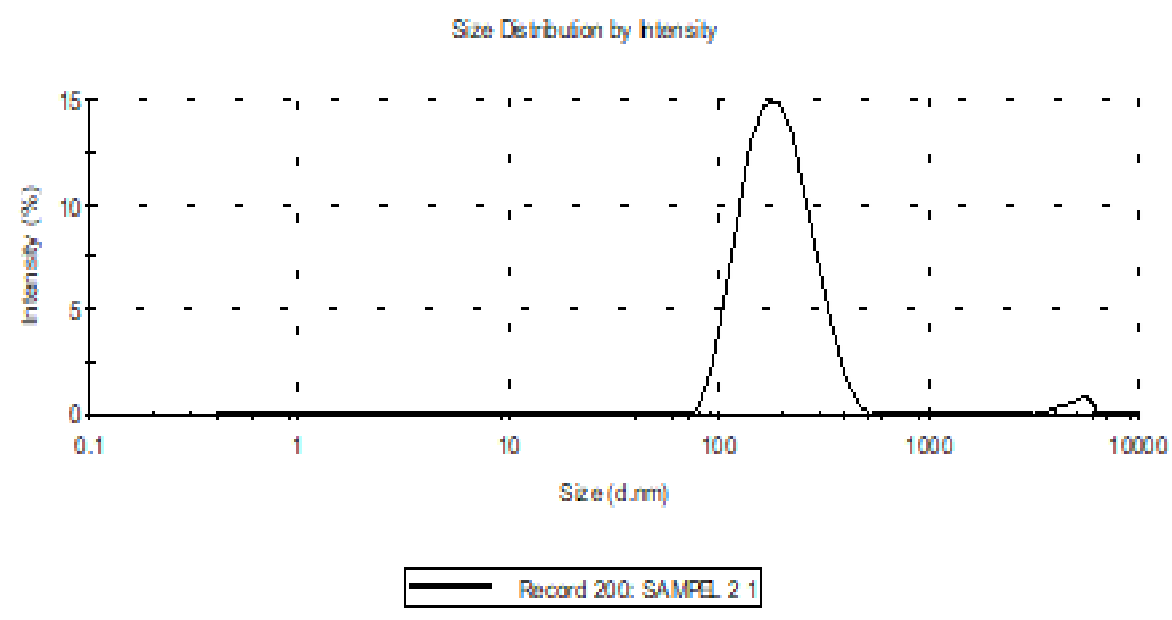

(a)

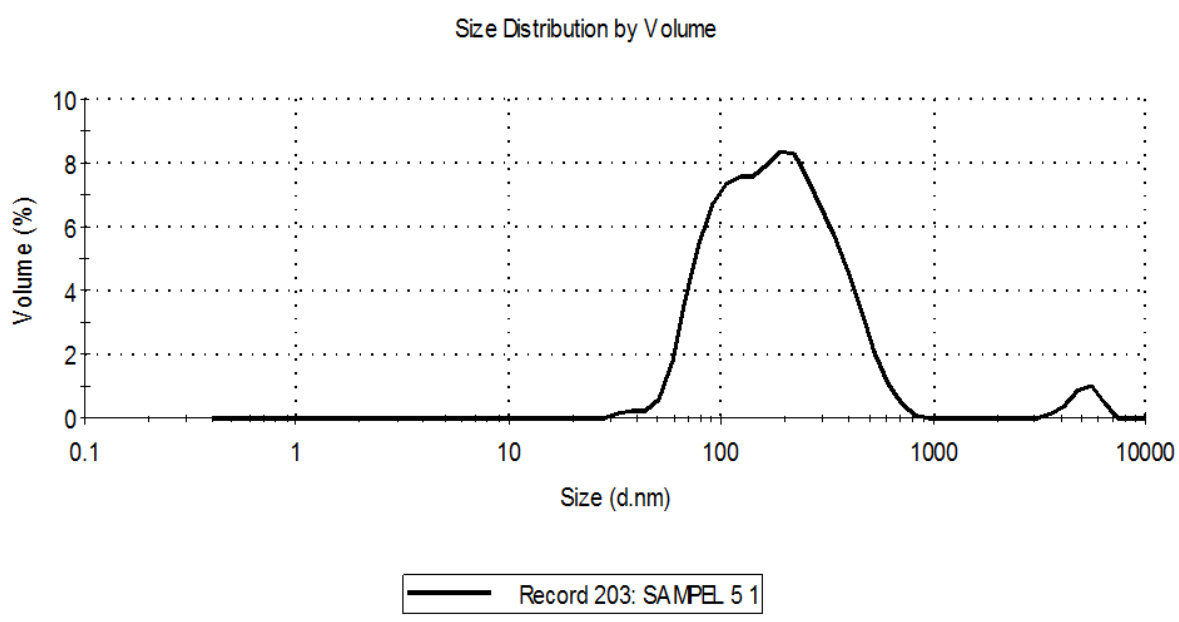

(b)

Figure 6 Particle sizes distribution of $\mathrm{TiO}_{2}$-water nanofluids synthesized by sequence procedures of (a) 2 and (b) 5

\section{CONCLUSION}

This study was carried out to find a new method for preparing $\mathrm{TiO}_{2}-$ water nanofluid with high thermal conductivity. The optimal conditions for preparing $\mathrm{TiO}_{2}-$ water nanofluid were found to be an addition of $8 \%$ volume fraction of $\mathrm{TiO}_{2} \mathrm{NPs}$, an adjusted $\mathrm{pH}$ of 8 , and a cationic surfactant of $0.0073-0.029 \mathrm{wt} \%$. The best sequencing methods were obtained for sequence procedure 2 using demineralized water as a base fluid and an $8 \%$ volume fraction of $\mathrm{TiO}_{2} \mathrm{NPs}$, followed by 
a 10 -minute sonication process and the addition of CTAB $(0.029 \mathrm{wt} \%)$. These results have a great potential for improving the thermal conductivity of $\mathrm{TiO}_{2}$-water nanofluid, which can be applied as a heat transfer in heat pipes. In conclusion, the addition of CTAB surfactant into the nanofluid can be used to minimize NP aggregation and improve the dispersion behavior of nanofluid.

\section{ACKNOWLEDGEMENT}

The financial support of this research from DIKTI by Kompetensi Grant, No. 0425/UN2.R12/HKP.05.00/2015 is gratefully acknowledged.

\section{REFERENCES}

Adiwibowo, M.T., Ibadurrohman, M., Slamet, 2018. Synthesis of ZnO Nanoparticles and Their Nanofluid Stability in the Presence of a Palm Oil-based Primary Alkyl Sulphate Surfactant for Detergent Application. International Journal of Technology, Volume 9(2), pp. 307-316

Ahlatli, S., Mare, T., Estelle, P., Doner, N., 2016. Thermal Performance of Carbon Nanotube Nanofluids in Solar Microchannel Collectors: An Experimental Study. International Journal of Technology, Volume 7(2), pp. 219-226

Assael, M.J., Metaxa, I.N., Arvanitidis, J., Christofilos, D., Lioutas, C., 2005. Thermal Conductivity Enhancement in Aqueous Suspensions of Carbon Multi-walled and Doublewalled Nanotubes in the Presence of Two Different Dispersants. International Journal of Thermophys, Volume 26(3), pp. 647-664

Bhattacharya, P., Saha, S.K., Yadav, A., Phelan, P.E., Prasher, R.S., 2004. Brownian Dynamics Simulation to Determine the Effective Thermal Conductivity of Nanofluid. Journal of Applied Physics, Volume 95(11), pp. 6492-6494

Das, P.K., Mallik, A.K., Ganguly, R., Santra, A.K., 2016. Synthesis and Characterization of $\mathrm{TiO}_{2}$-water Nanofluid with Different Surfactants. International Communications in Heat and Mass Transfer, Volume 75, pp. 341-348

Das, P.K., Mallik, A.K., Ganguly, R., Santra, A.K., 2018. Stability and Thermophysical Measurements of $\mathrm{TiO}_{2}$ (Anatase) Nanofluids with Different Surfactants. Journal of Molecular Liquids, Volume 254, pp. 98-107

Duangthongsuk, W., Wongwises, S., 2009. Measurements of Temperature-dependent Thermal and Viscosity of $\mathrm{TiO}_{2}$-water Nanofluid. Experimental Thermal and Fluid Science, Volume 33(4), pp. 706-714

Hong, T.K., Yang, H.S, Choi, C.J., 2005. Study of the Enhanced Thermal Conductivity of Fe Nanofluids. Journal of Applied Physics, Volume 97(6), pp. 1-4

Ismay, M.J.L., Doroodchi, E., Moghtaderi, B., 2013. Effects of Colloidal Properties on Sensible Heat Transfer in Water-based Titania Nanofluid. Chemical Engineering Research and Design, Volume 91(3), pp. 426-436

Jayasree, T.K., Predeep, P., Agarwal, R., Saxena, N.S., 2006. Thermal Conductivity and Thermal Diffusivity of Thermoplastic Elastomeric Blends of Styrene Butadiene Rubber/High Density Polyethylene: Effect of Blend Ratio and Dynamic Crosslinking. Trends in Applied Sciences Research, Volume 1(3), pp. 278-291

Jiang, L., Gao, L., Sun J., 2003. Production of Aqueous Colloidal Dispersions of Carbon Nanotubes. Journal of Colloid Interface Science, Volume 260(1), pp. 89-94

Jin, H., Xianju, W., Qiong, L., Xueyi Yunjin, W., Liming, Z.L., 2009. Influence of pH on the Stability Characteristics of Nanofluid. In: Symposium on Photonics and Optoelectronics, pp. 1-4

Leong, K.C., Yang, C., Murshed, S.M.S., 2006. A Model for the Thermal Conductivity of Nanofluid-The Effect of Interfacial Layer. Journal of Nanoparticles Resource, Volume 8(2), pp. 245-254 
Li, X.F., Zhu, D.S., Wang, X.J., Wang, N., Gao, J.W., Li, H., 2008. Thermal Conductivity Enhancement Dependent $\mathrm{pH}$ and Chemical Surfactant for $\mathrm{Cu}-\mathrm{H}_{2} \mathrm{O}$ Nanofluid. Thermochimica Acta, Volume 469(1-2), pp. 98-103

Maxwell, J.C., 1873. A Treatise on Electricity and Magnetism. Clarendon Press, Oxford, UK

Murshed, S.M.S., Leong, K.C., Yang, C., 2005. Enhanced Thermal Conductivity of $\mathrm{TiO}_{2}-$ waterbased Nanofluid. International Journal of Thermal Sciences, Volume 44(4), pp. 367-373

Murshed, S.M.S., Leong, K.C., Yang, C., 2008. Investigations of Thermal Conductivity and Viscosity of Nanofluid. International Journal of Thermal Sciences, Volume 47(5), pp. 560 568

Prasher, R., Phelan, P.E., Bhattacharya, P., 2006. Effect of Aggregation Kinetics on the Thermal Conductivity of Nanoscale Colloidal Solutions (Nanofluid). Nano Letters, Volume 6(7), pp. 1529-1534

Putra, N., Septiadi, W.N., Rahman, H., Irwansyah, R., 2012. Thermal Performance of Screen Mesh Wick Heat Pipes with Nanofluid. Experimental Thermal and Fluid Science, Volume 40, pp. 10-17

Rahman, A., Nurjayadi, M., Wartilah, R., Kusrini, E., Prasetyanto, E.A., Degermenci, V., 2018. Enhanced Activity of $\mathrm{TiO}_{2} / \mathrm{Natural}$ Zeolite Composite for Degradation of Methyl Orange under Visible Light Irradiation. International Journal of Technology, Volume 9(6), pp. 1159-1167

Saleh, R., Putra, N., Prakoso, S.P., Septiadi, W.N., 2013. Experimental Investigation of Thermal Conductivity and Heat Pipe Thermal Performance of ZnO Nanofluid. International Journal of Thermal Sciences, Volume 63, pp. 125-132

Saleh, R., Putra, N., Wibowo, R.E., Septiadi, W.N., Prakoso, S.P., 2014. Titanium Dioxide Nanofluid for Heat Transfer Applications. Experimental Thermal and Fluid Science, Volume 52, pp. 19-29

Sonawane, S.S., Khedkar, R.S., Wasewar, K.L., 2015. Effect of Sonication Time on Enhancement of Effective Thermal Conductivity of Nano $\mathrm{TiO}_{2}-$ water, Ethylene Glycol, and Paraffin Oil Nanofluid and Models Comparisons. Journal of Experimental Nanoscience, Volume 10(4), pp. 310-322

Vasiliev, L.L., 2005. Review Heat Pipes in Modern Heat Exchangers. Applied Thermal Engineering, Volume 25, pp. 1-19

Wang, X.J., Zhu, D.S., Yang, S., 2009. Investigation of pH and SDBS on Enhancement of Thermal Conductivity in Nanofluid. Chemical Physics Letters, Volume 470(1-3), pp. 107111

Xie, H.Q., Xi, T.G., Wang, J.C., 2003. Study on the Mechanism of Heat Conduction in Nanofluid Medium. Acta Physica Sinica, Volume 52(6), pp. 1444-1449

Yiamsawasd, T., Dalkilic, A.S., Wongwises, S., 2012. Measurement of the Thermal Conductivity of Titania and Alumina Nanofluid. Thermochimia Acta, Volume 545, pp. 48-56

Yu, W., Xie, H.A., 2012. Review on Nanofluid: Preparation, Stability Mechanisms, and Applications. Journal of Nanomaterials, Volume 2012, pp. 1-17

Zhen-Jian, H., Chun-Hua, T., Xu-Guang H., 2010. Determination of Surfactant CMC based on the Fiber Refractive Index Sensor Principle. Acta Physics Chimica Sinica, Volume 26, pp. 1271-1276

Zhou, M., Xia, G., Li, J., Chai, L., Zhou, L., 2012. Analysis of Factors Influencing Thermal Conductivity and Viscosity in Different Kinds of Surfactant Solutions. Experimental Thermal and Fluid Science, Volume 36, pp. 22-29

Zhu, D., Li, X., Wang, N., Wang, X., Gao, J., Li, H., 2008. A Dispersion Behavior and Thermal Conductivity Characteristics of $\mathrm{Al}_{2} \mathrm{O}_{3}-\mathrm{H}_{2} \mathrm{O}$ Nanofluid. Current Applied Physics, Volume 9(1), pp. 131-139 
Zulmajdi, S.L.N., Zamri, N.I.I., Mahadi, A.H., Rosli, M.Y.H., Ja'afar, F., Yasin, H.M., Kusrini, E., Hobley, J., Usman, A., 2019. Sol-gel Preparation of Different Crystalline Phases of $\mathrm{TiO}_{2}$ Nanoparticles for Photocatalytic Degradation of Methylene Blue in Aqueous Solution. American Journal of Nanomaterials, Volume 7(1), pp. 39-45 